\title{
Cutaneous Leishmaniasis: Recent Developments in Diagnosis and Management
}

\author{
Henry J. C. de Vries • Sophia H. Reedijk • \\ Henk D. F. H. Schallig
}

Published online: 17 February 2015

(c) The Author(s) 2015. This article is published with open access at Springerlink.com

\begin{abstract}
This review focuses on recent developments in the diagnosis, treatment, management, and strategies for the prevention and control of cutaneous leishmaniasis (CL) caused by both Old and New World Leishmania species. CL is caused by the vector-borne protozoan parasite Leishmania and is transmitted via infected female sandflies. The disease is endemic in more than 98 countries and an estimated 350 million people are at risk. The overall prevalence is 12 million cases and the annual incidence is $2-2.5$ million. The World Health Organization considers CL a severely neglected disease and a category 1 emerging and uncontrolled disease. The management of CL differs from region to region and is primarily based on local experience-based evidence. Most CL patients can be treated with topical treatments, but some Leishmania species can cause mucocutaneous involvement requiring a systemic therapeutic approach. Moreover, Leishmania species can vary in their sensitivity to available therapeutic options. This makes
\end{abstract}

\section{H. J. C. de Vries $(\varangle)$ · S. H. Reedijk}

Department of Dermatology, Academic Medical Center (AMC),

University of Amsterdam, P.O. Box 22700,

1100 DE Amsterdam, The Netherlands

e-mail: h.j.devries@amc.nl

\section{H. J. C. de Vries}

Center for Infection and Immunology Amsterdam (CINIMA), Academic Medical Center (AMC), University of Amsterdam, Amsterdam, The Netherlands

H. J. C. de Vries

STI Outpatient Clinic, Public Health Service of Amsterdam (GGD Amsterdam), Amsterdam, The Netherlands

H. D. F. H. Schallig

Parasitology Unit, Koninklijk Instituut voor de Tropen (KIT)/Royal Tropical Institute, KIT Biomedical Research, Amsterdam, The Netherlands species determination critical for the choice of treatment and the clinical outcome of CL. Identification of the infecting parasite used to be laborious, but now the Leishmania species can be identified relatively easy with new DNA techniques that enable a more rational therapy choice. Current treatment guidelines for $\mathrm{CL}$ are based on poorly designed and reported trials. There is a lack of evidence for potentially beneficial treatments, a desperate need for large wellconducted studies, and standardization of future trials. Moreover, intensified research programs to improve vector control, diagnostics, and the therapeutic arsenal to contain further incidence and morbidity are needed.

\section{Key Points}

Cutaneous leishmaniasis is an emerging uncontrolled and neglected infection affecting millions yearly.

With modern molecular techniques, Leishmania species determination is increasingly common and critical for the choice of treatment and the clinical outcome.

Current cutaneous leishmaniasis management is for a considerable part non-evidence based; therefore, intensified research programs to improve vector control, diagnostics, and the therapeutic arsenal are needed.

\section{Introduction}

Leishmaniasis is caused by vector-borne protozoan parasites of the genus Leishmania and transmitted via infected 
female sandflies (Phlebotomus and Lutzomyia). The disease is endemic in more than 98 countries and an estimated 350 million people are at risk. The overall prevalence is 12 million cases and the annual incidence is $2-2.5$ million cases. In most countries, the incidence numbers are probably underestimated because cases are not recognized and reporting is not mandatory [1].

Depending on the infecting species, an infection with Leishmania parasites can give rise to three clinical manifestations. The first is localized cutaneous leishmaniasis (CL) with single to multiple skin ulcers, satellite lesions, or nodular lymphangitis. The second is CL with mucosal involvement (MCL) and the third is systemic visceral leishmaniasis (VL) with involvement of internal organs, such as the liver, spleen, and bone marrow, which is lethal if not appropriately treated [2].

$\mathrm{CL}$ is worldwide the most prevalent clinical form of leishmaniasis, and $90 \%$ of all CL cases occur in only seven countries: Afghanistan, Algeria, Brazil, Iran, Peru, Saudi Arabia, and Syria [3]. According to the Eurocentric world view, Leishmania parasites are divided into Old World species: $L$. (L.) major, $L$. infantum, and $L$. (L.) tropica (prevalent around the Mediterranean basin, the Middle East, the horn of Africa, and the Indian subcontinent), and New World species, such as $L$. (L.) amazonensis, $L$. (L.) chagasi, L. mexicana $L, L$. (V.) naiffi, $L$. (V.) braziliensis, and $L$. (V.) guyanensis (endemic in Middle and South America). Whereas most Old World species cause selflimiting ulcers in most cases, New World species cause a syndrome called American tegumentary leishmaniasis comprising CL plus a variety of other manifestations, such as MCL and the much rarer diffuse and disseminated cutaneous leishmaniasis (DCL) [4].

Apart from the variety of species-driven clinical manifestations, Leishmania species vary in sensitivity to available therapies [5]. This makes species determination critical for the clinical outcome of leishmaniasis. In contrast to many other infectious diseases, identification of the infecting Leishmania parasite used to be laborious. Leishmania parasites can now be identified relatively easy with new DNA techniques.

Two recent Cochrane reviews on the current treatment for Old and New World CL conclude that most clinical treatment trials have been designed and reported poorly, resulting in a lack of evidence for potentially beneficial treatments $[6,7]$. This can in part be attributed to the lack of financial incentive for pharmaceutical companies to invest in the development of drugs for a disease that is believed to primarily affect people that lack financial resources. Moreover, drug trials for $\mathrm{CL}$ are challenging because the disease mainly occurs in remote areas; as a result, proper follow-up is problematic and many studies have been affected by a considerable number of loss to follow-up events. There is a desperate need for large wellconducted studies that evaluate long-term effects of current therapies, and it is suggested that an international platform should be created to improve the quality and standardization of future trials to inform clinical practice.

On World Health Day 2014, the World Health Organization (WHO) highlighted the serious and increasing threat of vector-borne diseases, including leishmaniasis, with the slogan "Small bite, big threat" [8]. As a category 1 emerging and uncontrolled disease, leishmaniasis is considered a severely neglected disease and intensified research programs to improve vector control, diagnostics, and the therapeutic arsenal to contain further incidence and morbidity are needed. In this review, we focus on recent developments in the diagnosis, treatment, prevention, and strategies for the management and control of CL caused by both Old and New World species.

We performed a literature search for articles in PubMed published between 2012/01/01 and 2014/10/31 and filtered on the mesh terms humans and cutaneous leishmaniasis or cutaneous leishmania. The following publication languages were included: English, French, Spanish, and Portuguese. The search was narrowed down by using the following items: prevention or control or therapy/narrow[filter] or diagnosis/broad[filter] or clinical trial[ptyp] or classical article[ptyp] or comparative study[ptyp] or clinical trial, phase i[ptyp] or clinical trial, phase ii[ptyp] or clinical trial, phase iii[ptyp] or clinical trial, phase iv[ptyp] or controlled clinical trial[ptyp] or evaluation studies[ptyp] or guideline[ptyp] or multicenter study[ptyp] or review[ptyp] or practice guideline[ptyp] or randomized controlled trial[ptyp] or systematic[sb] or validation studies[ptyp].

\section{Laboratory Diagnosis}

The diagnosis of CL is based on clinical features (supported by epidemiologic data) and laboratory testing. Numerous diagnostic methods have been described with a huge variation in diagnostic accuracy, including direct parasitologic examination (microscopy, histopathology, and parasite culture) and/or indirect testing with serology and molecular diagnostics [9]. The selection of the diagnostic test employed often depends on the available infrastructure and resources of the diagnostic facility and not on diagnostic accuracy. Here, we selected only general employed diagnostic methodologies for discussion.

\subsection{Direct Microscopy, Histopathology, and Culture}

Parasitologic diagnosis is still considered the gold standard in leishmaniasis diagnosis because of its high specificity. This is typically undertaken by histopathologic examination 
of fixed tissue or parasite in vitro culture from material from suspected lesions. Microscopical diagnosis of CL is performed by the direct identification of amastigotes in Giemsa-stained lesion smears of biopsies, scrapings, or impression smears. Amastigotes appear as round or oval bodies, about 2-4 $\mu \mathrm{m}$ in diameter, with characteristic nuclei and kinetoplasts (Fig. 1). The material from the ulcer margin usually has the highest yield. A comparative study between widely used scraping smears and fine needle aspiration cytology found a significant difference between the two methods in favor of fine needle aspiration in the detection of amastigotes and microgranuloma, slide background, and patient comfort [10]. A simplified collection method is the press-imprint-smear (PIS). When compared with histopathology for the diagnosis of CL, PIS was positive in $85.3 \%$ in study cases suspected of CL, and histopathology was only positive in $44 \%$. PIS is considered a rapid and relatively sensitive method for the diagnosis of CL [11].

Parasite culture in tubes containing Novy-MacNeal-Nicolle medium from suspected lesions is difficult, requires significant technical expertise, is prone to contamination, and is time consuming [12]. The sensitivity of culture tends to be low and highly variable [13]. Recently developed mini- and micro-culture technologies have the advantage of being less costly because of the smaller volume of culture medium required, easier to use, and more sensitive, even when the parasite burden is low [12]. A disadvantage of micro-culture is that this technology does not allow for further species determination. In a recent study, the performance of micro-culture was assessed on 273 subjects who fulfilled the criteria for CL. Sensitivity and specificity for micro-culture were $98.4 \%$ (95\% CI $=96.1-99.1 \%$ ) and $100.0 \%$, respectively [14]. Additional advantages of

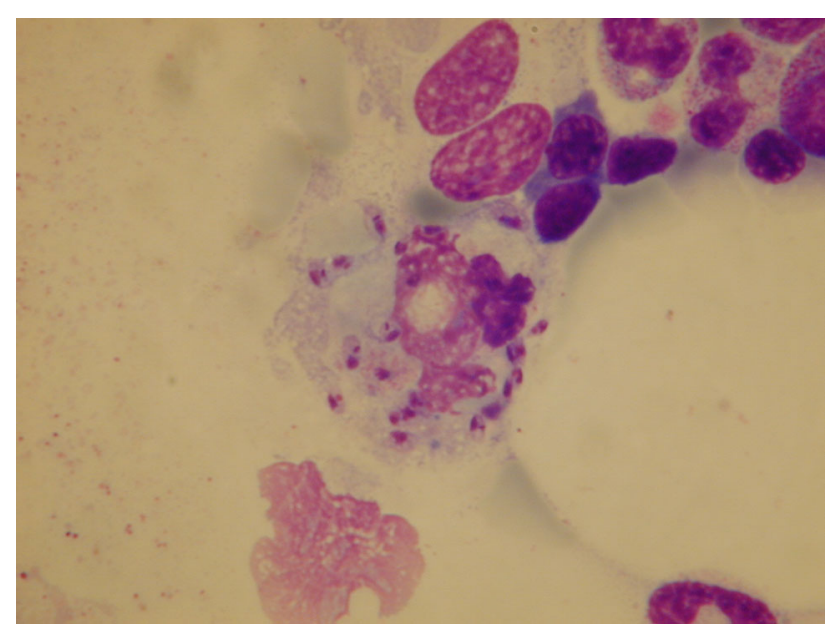

Fig. 1 Leismaniasis amastigotes. In the skin, amastigotes appear as intracellular round or oval bodies, about $2-4 \mu \mathrm{m}$ in diameter, with characteristic nuclei and kinetoplasts this method are simplicity and the fact that diagnostic samples are retrieved by a needle-free method.

\subsection{Imunologic Diagnostic Methods}

Current serologic tests for CL are mainly based on formats such as indirect fluorescent antibody, enzyme-linked immunosorbent assay (ELISA), western blot, lateral flow assay, and direct agglutination test. However, these formats are not widely employed for the diagnosis of CL, because of the poor humoral response provoked by the infection and the consequential low sensitivity [9, 15].

Furthermore, most currently available serologic tests are preliminary based on either a total parasite lysate or whole promastigote yielding in aspecific reactions. Recent developments suggest that incorporation of specific purified antigen preparations or recombinant Leishmania antigens for serologic diagnosis would increase the operational characteristics of these tests. This is following the success of the rK39 antigen for the sero-diagnosis of VL [16]. Heat shock proteins (HSPs), and in particular HSP83, have appeared as potential candidates. An ELISA based on recombinant HSP83 has shown good performance in the diagnosis of CL, next to ML and VL, compared with an ELISA-based crude L. major antigen in terms of sensitivity and specificity. Furthermore, using a chemiluminescent ELISA to measure levels of anti- $\alpha$-galactosyl antibodies in human sera, it was found that individuals infected with either L. tropica or L. major had significantly elevated levels (up to 9-fold higher) of anti- $\alpha$-Gal IgG compared with healthy control individuals [17]. In addition, the assay had higher sensitivity than microscopy analysis. Interestingly, up to 2 years following confirmed CL cure, individuals had 28-fold higher levels of anti- $\alpha$-Gal IgG compared with healthy volunteers. Monitoring levels of anti- $\alpha$-Gal antibodies is proposed as both a diagnostic tool and as a biomarker of a cure of Old World CL [17].

An innovative diagnostic test that is currently under evaluation is the CL Detect ${ }^{\mathrm{TM}}$ Rapid Test, which is a qualitative membrane-based immunoassay for the detection of all clinically relevant species of the genus Leishmania that cause CL in skin samples. The test is currently being evaluated (http://clinicaltrials.gov/show/NCT01865032).

\subsection{Leishmania Skin Test}

The Leishmania intradermal skin test (LST) or Montenegro skin test (MST) is a marker of cellular immune response and occasionally used in CL diagnosis (e.g., in epidemiologic surveys and vaccine studies) because of its simple use and because of its high sensitivity of $86.4 \%$ up to $100 \%$ [18]. Delayed-type hypersensitivity skin reactions to $\mathrm{LST} \geq 5 \mathrm{~mm}$ are considered positive and $<5 \mathrm{~mm}$ 
are considered negative. Patients with negative LST and diagnostic confirmation by other tests are more prone to relapse or treatment failure $[18,19]$. The main disadvantages of the LST or MST are that it requires culture facilities to produce the MST antigen, that different antigen preparations impact test sensitivity, and that the test does not distinguish between past and present infections [20].

There is evidence that when LST data are supported with information on the production of antigen-specific interferon- $\gamma$ (IFN- $\gamma$ ), this could better assist in determining whether a suspected case has been exposed to a Leishmania infection [21]. In contrast, it is reported that the LST is significantly more sensitive than IFN- $\gamma$ levels in persons who have been cured of CL [22].

\subsection{Nucleic Acid Amplification Tests}

\subsubsection{Polymerase Chain Reaction (PCR)}

Many molecular diagnostic tests have been developed for the diagnosis of CL, as these are assumed to have better sensitivity and specificity than traditional diagnostic methods and allow the use of less invasive sampling for diagnosis [23, 24]. In particular PCR, either as a single test or in a nested format or as a quantitative assay, has been widely exploited. Numerous tests targeting many different gene sequences have been developed over the last decades, with the ribosomal DNA internal transcribed spacer 1 sequence [25-27], or sequences within the kinetoplast DNA of Leishmania genus as the main targets [28, 29]. Next to this, several other PCR-like assays, such as a high-tech fluorescence resonance energy transfer based on a real-time assay [23, 30], or assays based on HSP70 or tryparedoxin peroxidase gene targets $[31,32]$ amongst many others, are under evaluation.

As there are no defined general accepted protocols and almost each laboratory applies its own in-house method, a head-to-head comparison of the different PCR methods needs to be undertaken. In particular, studies addressing inter-laboratory comparisons are scarce and the initiative by Cruz and co-workers [24] who proposed a protocol for inter-laboratory comparisons of conventional and real-time PCR methods should be taken on.

\subsubsection{Isothermal Platforms}

PCR requires adequate infrastructure and technically skilled operators, making tests based on this platform less suitable for resource-restricted laboratories in disease-endemic countries. In an attempt to partly circumvent these requirements, isothermal diagnostic platforms have been developed in recent years. Nucleic acid sequence-based amplification, an isothermal reaction targeting parasite
RNA, has been developed for leishmaniasis [33]. Oligochromatography for post-amplification analysis further circumvents the use of complex equipment while preserving appropriate diagnostic performance characteristics [21, 34, 35].

A further development in isothermal molecular diagnostics is loop-mediated isothermal reaction (LAMP), which is performed at 60 and $65{ }^{\circ} \mathrm{C}$, uses only one enzyme (Bst DNA polymerase) for amplification, and is able to produce large amounts of DNA within 30-60 min. Importantly, the specificity of the reaction is high because it uses six primers and the end product can be visualized directly using simple detection methods [36].

The initial LAMP test for CL was a generic reverse transcriptase (RT-)LAMP, targeting the conserved region of the 18S ribosomal RNA gene. Amplification was visualized by the pre-amplification addition of fluorescent detection reagent and a simple ultraviolet lamp. By using a reverse-transcriptase step, the system detected infections between 10 and 100 parasites per $\mathrm{mL}$ and the sensitivity of RT-LAMP for CL patients was $98 \%$ [36]. Different research groups further developed this technology for various applications [37-39].

The application of LAMP on boiled swab samples is an interesting advance to develop a simple and rapid (pointof-care) diagnostic method for CL [40, 41]. This approach has the potential advantages of using LAMP as a molecular diagnostic test in endemic regions where medical resources are limited.

\subsubsection{Sampling for Molecular Biology}

Non-invasive sampling for Leishmania detection is essential for quick and affordable diagnosis. However, a significant variation in clinical accuracy of molecular diagnostic methods for CL is commonly observed, depending on the sample source, the method of DNA recovery, and the molecular test, and only a few attempts have been made to compare these variables [42]. Adams and co-workers evaluated two swab and aspirate samples from lesions of patients with suspected CL alongside standard diagnosis by microscopic detection of amastigotes or culture of parasites from lesion material. Swab sampling, which is painless and simple to perform, combined with Qiagen ${ }^{\circledR}$ DNA extraction proved the most efficient, sensitive, and specific recovery method for Leishmania DNA [42].

Flinders Technology Associates $\left(\mathrm{FTA}^{\circledR}\right.$ ) cards (Whatman filter paper cards) have also been successfully used to collect samples, including DNA specimens for PCR analysis. This method is minimally invasive for patients, easy to handle for medical personnel, and can easily be transported for analysis [43, 44]. 
Recently, other body samples, such as conjunctival swabs, are being considered as a source for CL tests but will require further research $[45,46]$.

\subsection{Species Determination}

Under a light microscope, all Leishmania species are morphologically undistinguishable from each other, yet species or strain identification is very relevant for patient management (see next paragraph) [5, 47]. For several decades, isoenzyme analysis of Leishmania has been used for strain typing and this has allowed the construction of phylogenetic classifications [48], and even the differentiation between antroponotic and zoonotic variants within a single species [49]. This methodology is based on variation in the electrophoretic mobility of enzymes isolated from Leishmania parasites. Strains are consigned to various zymodemes. This highly specialized method is performed in a few reference laboratories only, because it is costly, time consuming, and requires large quantities of cultured promastigotes [50]. Therefore, alternative typing methods are being developed, in particular, based on genetic characteristics of the parasite. PCR-based methods in combination with restriction fragment length polymorphism analysis or sequencing enable correct species discrimination. Over the last decade, several gene targets have been identified for this purpose. A widely employed target is the mini-exon gene, which is involved in the trans-splicing process of nuclear messenger RNA, and is present as 100-200 tandem repeated copies per nuclear genome. Each repeat consists of three major parts that make the mini-exon an excellent genotyping marker [51]. Marfurt and coworkers [51, 52] have developed a widely used typing technology comprising a PCR assay amplifying all the mini-exon sequences in a single reaction using universal primers, allowing preliminary discrimination between the major complexes (i.e., Old World Leishmania, New World Leishmania, and New World Viannia complexes) as a result of the variability in sizes of the amplification products. The mini-exon PCR-RFLP (Restriction Fragment Length Polymorphism) genotyping scheme was validated with cultured WHO reference strains of Leishmania and cultured isolates from patients [51, 52]. This methodology is now widely employed as a highresolution, sensitive, and specific tool that can identify all clinically relevant Leishmania species [5, 53-55].

Alternative candidate genes for typing are HSP70, hexokinase, and phosphoglucomutase genes for several Old World species [50] and HSP70 gene regions for New World species [56, 57]. HSP70-based species identification tools are potentially globally applicable in different clinical and sampling contexts, and they could become the reference method for identification of Leishmania species in clinical specimens [58].

\section{Species-Based Clinical Management}

In many low-resource settings, CL is diagnosed without laboratory confirmation tests, and a probable CL case has to be identified based solely on the patient history and physical examination. Risk factors for CL to be addressed during history taking are: young age, professions involving farming, hunting, military, and mining activities (Fig. 2), denying the use of bed nets, exposure in rural, sub-urban, or deforested sites (Fig. 3), presence of pets and cattle, travel (immunologically naïve cases entering a CL-endemic area such as tourists and labor migrants are more often affected), and the season of exposure (rainy seasons and El Niño are associated with CL) [59-63]. Physical signs suspected for $\mathrm{CL}$ are crustaceous ulcerative lesions on unexposed areas such as the extremities and face, the presence of satellite lesions (Fig. 4), and/or lymphangitis (Fig. 5). In the case of MCL, the involvement of mucosal tissue in the ear, nose, and throat tract should be excluded.

A more definite diagnosis to base further clinical management on can be made with non-specific diagnostic tests (e.g., light microscopy). These tests do not allow for species identification and Leishmania species vary in their sensitivity to available drugs [64]. If one species is dominating an endemic geographic region, the preferred treatment can be based on local (trial- and error-based) experience. However, geographically driven treatment is

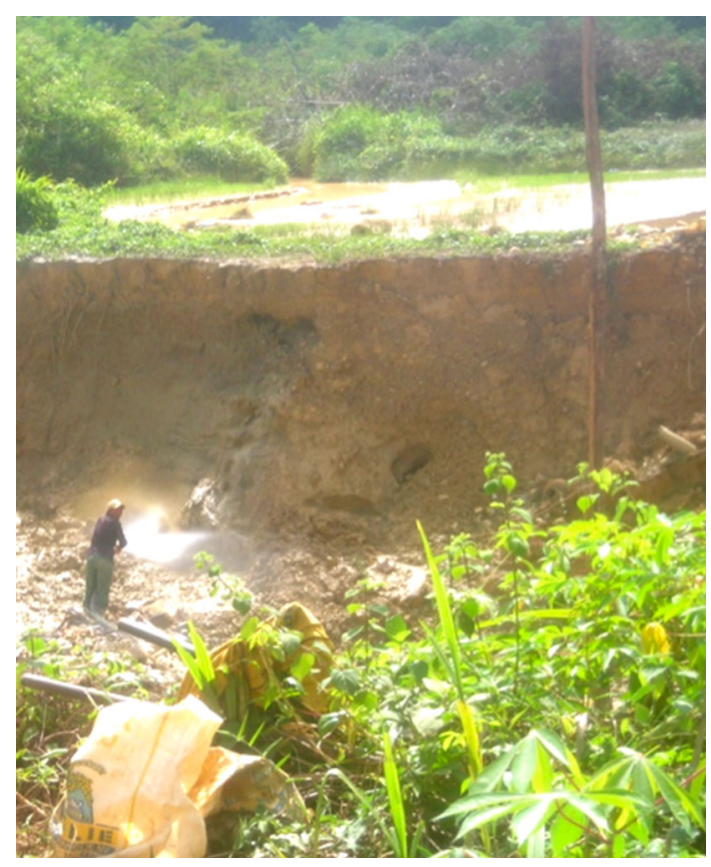

Fig. 2 Gold mining in West Suriname. A gold digger (garimpeiros) at work in a highly leishmaniasis-endemic area, Benzdorp, district Sipaliwini, in Suriname. Miners are a well-known risk group for cutaneous leishmaniasis. Collection Ramdas (2010) 


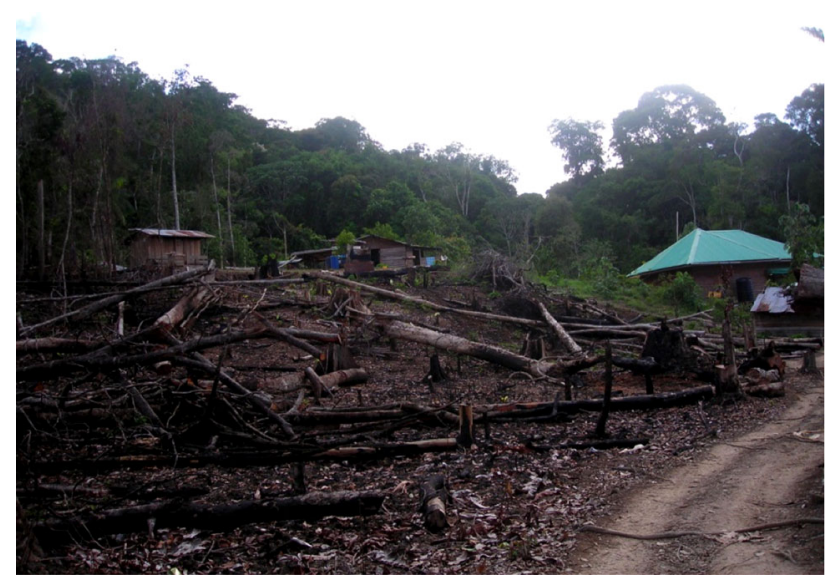

Fig. 3 Deforestation in Godo-olo, district Sipaliwini (Suriname). Human interference can cause leishmaniasis outbreaks owing to the disruption of the natural reservoir-vector transmission cycle of Leismania parasites and the introduction of an immune naïve labor force in the deforested area. Collection Ramdas (2009)

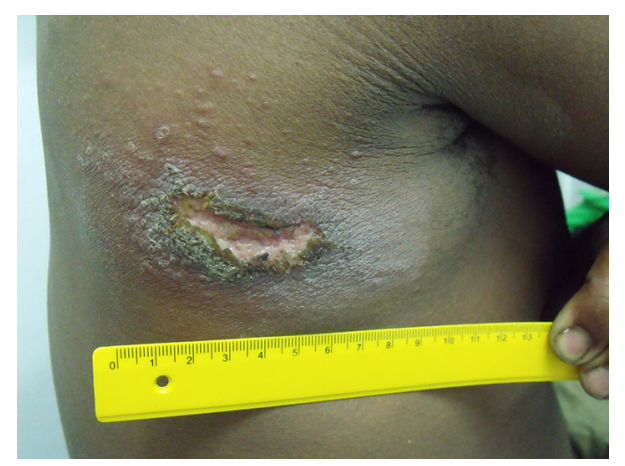

Fig. 4 Satellite lesions in cutaneous leishmaniasis. Local dissemination of Leishmania parasites from the primary lesion into the surrounding skin can give rise to satellite lesions. Collection Dr. $\mathrm{Hu}$, Dermatological Service, Paramaribo, Suriname

inadequate in many endemic regions where multiple Leishmania species prevail, of which each require a different therapy. For example, in many settings in Middle and South America, species causing both CL and MCL are endemic in the same regions [65-67]. Because leishmaniasis manifestations require different management (see next paragraph), it is important to know which species is involved for the best treatment outcome, with the least side effects and late complications [68, 69].

For appropriate and effective clinical management, it is important that cheap and reliable species-specific diagnostic tests become available, especially in cases where treatment failure arises. In low-resource settings where healthcare infrastructure is sparse, rapid diagnostics are also critical to deliver timely treatment (preferably at the first consultation), thus preventing loss to follow-up due to required return visits. CL species-specific driven

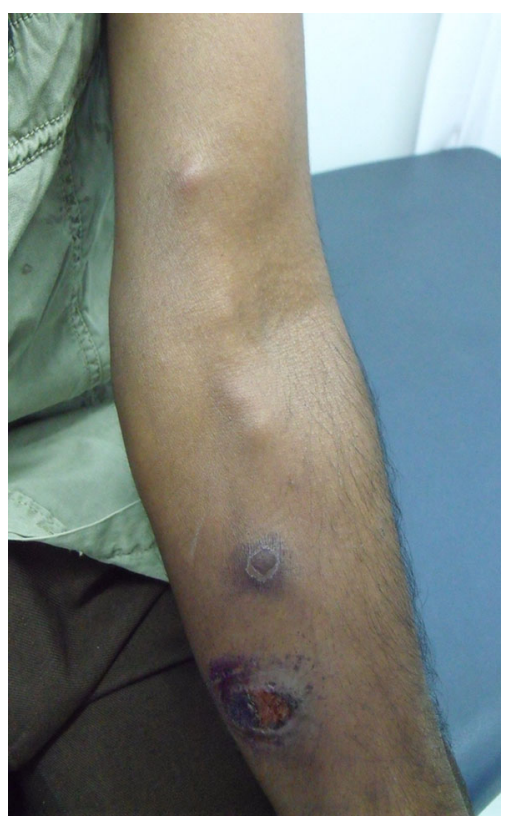

Fig. 5 Lymphangitis in cutaneous leishmaniasis. Loco-regional dissemination of Leishmania parasites via lymphatics can cause lymphangitis (also known as sporotrichoid dissemination, after the similar clinical picture seen in deep fungal infections). Collection Dr. $\mathrm{Hu}$, Dermatological Service, Paramaribo, Suriname

management is also important in non-endemic settings where travelers with CL are seen, especially if different endemic areas have been visited and the causative species is unclear $[5,61]$.

Species determination is also important for clinical trials because the outcome is affected by the species infecting the participants. A Cochrane review on the treatment of New World CL found that 4 out of 38 trials failed to mention the causative parasite [70]. Six trials mentioned the endemic nature of the parasite in the area and therefore assumed that the specific parasite strain was the species causing the development of the disease. Another two trials accepted that the parasites species were the same as in previous studies, and only 26 studies confirmed the causative species.

\section{Treatment}

In the majority of cases, CL is a self-healing disease. Nonetheless, nodular lymphangitis and MCL can lead to disabling and atrocious tissue destruction. Full recovery can take months to years, and this period can be characterized by function impairment, susceptibility to secondary infection, and the development of disfiguring permanent scars. Because little evidence-based data are available, most therapy options have to rely on expert opinions [5]. In many settings where species identification is unavailable, 
the mode of therapy is mainly based on local expertise only. Most of the currently available therapeutic options are associated with significant toxicity and side effects. Therefore, a risk-benefit assessment must be made by an experienced clinician for each CL patient, and, in mild and indolent cases, a wait-and-see policy can sometimes be the best advisable option. Moreover, drug resistance is an emerging problem in the control of CL [64].

Several treatment options for CL are available. Pentavalent antimonals (sodium stibogluconate, Pentostam ${ }^{\circledR}$ or meglumine antimoniate, Glucantime ${ }^{\circledR}$ ) remain the firstchoice treatment for $\mathrm{CL}$ in most countries. Alternative treatment regimens include miltefosine, pentamidine isethionate, amphotericin $\mathrm{B}$, antifungal agents (e.g., ketoconazole, fluconazole, itraconazol), paromomycine, granulocyte macrophage colony-stimulating factor, and heat therapy or cryotherapy $[6,70]$.

\subsection{Treatment of Old World CL}

In cases of a few (less than five) lesions, local therapy is preferred [5]. Local treatment combining intralesional antimony and cryotherapy proved more effective than antimony or cryotherapy alone, although as monotherapies, both also show high cure rates [71-73]. Heat therapy has also proven to be effective but requires special equipment $[74,75]$. Systemic treatment can be considered for multiple lesions, disfiguring facial lesions, or lesions at sites that make topical treatment less desirable. Systemic (oral) miltefosine treatment is a promising option for patients with multiple or complicated Old World CL (L. major) lesions $[76,77]$.

\subsection{Treatment of New World CL}

Like for Old World CL, local treatment is also a good option in the case of a limited number of lesions caused by New World strains that do not cause MCL like $L$. naiffi, $L$. chagasi, and L. mexicana $[78,79]$. When systemic treatment is needed for CL caused by L. mexicana, antimony is preferred because this strain shows resistance to miltefosine in in vitro and in vivo studies $[80,81]$. L. panamensis or L. amazonensis rarely cause MCL, suggesting that there is no need for systemic treatment in closely monitored cases [82]. Therefore, in uncomplicated CL cases caused by the latter strains, combination local therapy of antimony and cryotherapy is advised instead of systemic therapy [5]. For single uncomplicated lesions caused by L. guyanensis, local therapy with antimony and cryotherapy can be considered, although MCL due to L. guyanensis is not as rare as formerly thought [83]. Systemic pentamidine is the treatment of choice for L. guyanensis lesions in Suriname and Guyana, but recent evidence from Manaus, Brazil, shows efficacy of only about 50-60\% [84]. As a general advice in the case of New World CL, extensive follow-up to exclude treatment failure including MCL manifestations is advisable $[85,86]$.

Because of the considerable risk of MCL, local therapy is not recommended for infections caused by L. braziliensis. Nevertheless, the dogma that $L$. braziliensis infection has to be treated systemically has been debated [70, 82]. Systemic antimony is considered the gold standard treatment for L. braziliensis infections. Miltefosine shows comparable results, although treatment success shows geographic variations, possibly related to differences in parasite strains [87-89]. Amphotericin B treatment shows at least equivalent results as antimony treatment but is considered an alternative treatment because of considerably more serious side effects and related costs [90-92].

Because no evidence of specific treatment is available, the proposed treatment of MCL caused by L. panamensis, L.amazonensis, and $L$. guyanensis is as for MCL due to $L$. braziliensis [5]. Two small studies on the combination of antimony and pentoxifylline showed high cure rates of MCL and can be considered in the case of treatment failures in patients previously treated with a single modality [93, 94].

\section{Prevention}

Prevention is better than cure, both for the patient as well as the community at large. It is therefore an important tool in the control of CL. Primary prevention can be achieved by identifying risk groups and tackling known risk factors to prevent sandfly bites, such as farming, hunting, military, and mining activities without the protection of insecticides and clothing [59, 95].

In CL-endemic areas, it is also important to minimize the risk of sandfly bites during night rest. Because sandflies are very small, bed nets with a maze three times smaller as compared with bed nets for the prevention of malaria are required. Moreover, bed nets should be impregnated with permethrin or another effective insect repellent to further reduce the chance of sandfly bites.

Intervention programs focused on the natural reservoir of Leishmania have also been tried but with mixed efficiency. One study on vaccinating dogs with a prophylactic vaccine found a significant reduction in the amount of Leishmania cases in humans [95]. Impregnated dog collars and the treatment of dogs with insecticide drops have also shown a significant reduction in leishmaniasis disease burden. In contrast, in a large intervention campaign performed between 1988 till 1996 in Brazil, 150,000 Leishmania seropositive dogs were culled and over 1 million houses sprayed with insecticide, in an attempt to reduce the 
transmission of VL [96]. Disappointingly, no evidence could be shown on the mortality and morbidity. All in all, sound evidence on the effectiveness of interventions targeted at reservoir-to-human transmission is lacking.

Education is in many cases a very cost-effective preventive measure [62]. Informing populations in CL-endemic areas leads to a better uptake of preventive measures, lower risk behavior, and earlier help-seeking behavior, diagnosis, and treatment. A cost-effectiveness study conducted in Argentina estimated the gain of combined prevention strategies for CL-endemic areas, including the implementation of insecticide-impregnated clothing and curtains plus early CL diagnosis training programs for healthcare workers [97]. With the insecticide intervention only, 220.71 disability-adjusted life-years (DALYs) per 100,000 inhabitants could be prevented at a cost of US $\$ 13,155.52$ per DALY. The training program would not lower the prevalence of CL, but could prevent 170.63 DALYs per 100,000 inhabitants at a cost of only US $\$ 156.46$ per DALY averted. Both strategies would cost less than three times the gross domestic product per capita and can thus be considered cost efficient according to the criteria of the WHO.

\subsection{Future Preventive Measures, Vaccination}

Like many parasitic infections, CL has the ability to induce little immune stimulation through the continuous variation of antigenic epitopes and immunosuppressive mechanisms [98]. These immune-evasive characteristics impose a serious challenge on the development of an effective CL vaccine [99]. A naturally recovered CL induces life-long immunity against the species that caused the primary infection. This suggests that vaccination should somehow be possible and this has led to significant research efforts in this field. However, to date there are no human vaccines available for use in vaccination programs.

\section{Conclusions}

CL is emerging as, and threatens to become an uncontrollable disease. Most CL patients live in low- to middleincome countries where governments are faced with limited healthcare budgets and a large burden caused by other ailments such as malaria, tuberculosis, and HIV. As a result, little research is dedicated to the diagnosis, management, and control of CL.

Current CL treatment guidelines are based on poorly designed and ill-reported trials. Leishmania species can now be identified relatively easily with modern molecular techniques enabling a more rational therapy choice. However, there is a lack of evidence for potentially beneficial treatments, and a desperate need for large well-conducted studies and the standardization of future trials. Moreover, pharmaceutical companies invest too little in the development of new treatment modalities for CL because they are afraid their expenses will not be returned by sufficient income in the future. Novel less toxic treatment modalities are required. Especially for children, therapeutic modalities that can be administered without painful injections are required. Intensified research programs to improve vector control and diagnostics, and provide efficient and safe vaccines to contain further incidence and morbidity of CL are urgently needed.

Conflict of interest Henry de Vries, Sophia Reedijk and Henk Schallig have no conflicts of interest that are directly relevant to the content of this review. No funding was received for the preparation of this manuscript.

Open Access This article is distributed under the terms of the Creative Commons Attribution Noncommercial License which permits any noncommercial use, distribution, and reproduction in any medium, provided the original author(s) and the source are credited.

\section{References}

1. McGwire BS, Satoskar AR. Leishmaniasis: clinical syndromes and treatment. QJM. 2014;107(1):7-14. doi:10.1093/qjmed/hct116.

2. Bailey MS, Lockwood DN. Cutaneous leishmaniasis. Clin Dermatol. 2007;25(2):203-11. doi:10.1016/j.clindermatol.2006.05. 008.

3. Hepburn NC. Cutaneous leishmaniasis: current and future management. Expert Rev Anti Infec Ther. 2003;1(4):563-70.

4. Martins AL, Barreto JA, Lauris JR, Martins AC. American tegumentary leishmaniasis: correlations among immunological, histopathological and clinical parameters. An Bras Dermatol. 2014;89(1):52-8. doi:10.1590/abd1806-4841.20142226.

5. Hodiamont CJ, Kager PA, Bart A, de Vries HJ, van Thiel PP, Leenstra $\mathrm{T}$, et al. Species-directed therapy for leishmaniasis in returning travellers: a comprehensive guide. PLoS Negl Trop Dis. 2014;8(5):e2832. doi:10.1371/journal.pntd.0002832.

6. Gonzalez U. Cochrane reviews on neglected diseases: the case of cutaneous leishmaniasis. Cochrane Database Syst Rev. 2013;3: ED000055. doi:10.1002/14651858.ED000055.

7. Reveiz L, Maia-Elkhoury AN, Nicholls RS, Romero GA, Yadon ZE. Interventions for American cutaneous and mucocutaneous leishmaniasis: a systematic review update. PloS One. 2013;8(4): e61843. doi:10.1371/journal.pone.0061843.

8. Savioli L, Velayudhan R. Small bite, big threat: World Health Day 2014. East Mediterr Health J, La revue de sante de la Mediterranee orientale, al-Majallah al-sihhiyah li-sharq almutawassit. 2014;20(4):217-218.

9. Goto H, Lindoso JA. Current diagnosis and treatment of cutaneous and mucocutaneous leishmaniasis. Expert Rev Anti Infect Ther. 2010;8(4):419-33. doi:10.1586/eri.10.19.

10. Hosseinzadeh M, Omidifar N, Lohrasb MH. Use of fine needle aspiration cytology in the diagnosis of cutaneous leishmaniasis: a comparison with the conventional scraping method. Trop Doct. 2012;42(2):112-3. doi:10.1258/td.2011.110420.

11. Sousa AQ, Pompeu MM, Frutuoso MS, Lima JW, Tinel JM, Pearson RD. Press imprint smear: a rapid, simple, and cheap 
method for the diagnosis of cutaneous Leishmaniasis Caused by Leishmania (Viannia) braziliensis. Am J Trop Med Hyg. 2014;91(5):905-7. doi:10.4269/ajtmh.14-0160.

12. Boggild AK, Miranda-Verastegui C, Espinosa D, Arevalo J, Martinez-Medina D, Llanos-Cuentas A, et al. Optimization of microculture and evaluation of miniculture for the isolation of Leishmania parasites from cutaneous lesions in Peru. Am J Trop Med Hyg. 2008;79(6):847-52.

13. Faber WR, Oskam L, van Gool T, Kroon NC, Knegt-Junk KJ, Hofwegen $\mathrm{H}$, et al. Value of diagnostic techniques for cutaneous leishmaniasis. J Am Acad Dermatol. 2003;49(1):70-4. doi:10. 1067/mjd.2003.492.

14. Pagheh A, Fakhar M, Mesgarian F, Gholami S, Ahmadpour E. An improved microculture method for diagnosis of cutaneous leishmaniasis. J Parasit Dis. 2014;38(4):347-51. doi:10.1007/s12639013-0316-3.

15. Kar K. Serodiagnosis of leishmaniasis. Crit Rev Microbiol. 1995;21(2):123-52. doi:10.3109/10408419509113537.

16. Maia Z, Lirio M, Mistro S, Mendes CM, Mehta SR, Badaro R. Comparative study of rK39 Leishmania antigen for serodiagnosis of visceral leishmaniasis: systematic review with meta-analysis. PLoS Negl Trop Dis. 2012;6(1):e1484. doi:10.1371/journal.pntd. 0001484.

17. Al-Salem WS, Ferreira DM, Dyer NA, Alyamani EJ, Balghonaim SM, Al-Mehna AY, et al. Detection of high levels of anti-alphagalactosyl antibodies in sera of patients with Old World cutaneous leishmaniasis: a possible tool for diagnosis and biomarker for cure in an elimination setting. Parasitology. 2014;141(14): 1898-903. doi:10.1017/S0031182014001607.

18. de Fátima Antonio L, Fagundes A, Oliveira RV, Pinto PG, BedoyaPacheco SJ, de Camargo Ferreira e Vasconcellos E, et al. Montenegro skin test and age of skin lesion as predictors of treatment failure in cutaneous leishmaniasis. Rev Inst Med Trop Sao Paulo. 2014;56(5):375-80. doi:10.1590/S0036-46652014000500002

19. Passos VM, Barreto SM, Romanha AJ, Krettli AU, Volpini AC, Lima e Costa MF. American cutaneous leishmaniasis: use of a skin test as a predictor of relapse after treatment. Bull World Health Organ. 2000;78(8):968-74.

20. Weigle KA, Valderrama L, Arias AL, Santrich C, Saravia NG. Leishmanin skin test standardization and evaluation of safety, dose, storage, longevity of reaction and sensitization. Am J Trop Med Hyg. 1991;44(3):260-71.

21. Schnorr D, Muniz AC, Passos S, Guimaraes LH, Lago EL, Bacellar $\mathrm{O}$, et al. IFN-gamma production to leishmania antigen supplements the leishmania skin test in identifying exposure to $\mathrm{L}$. braziliensis infection. PLoS Negl Trop Dis. 2012;6(12):e1947. doi:10.1371/journal.pntd.0001947.

22. Alimohammadian MH, Jones SL, Darabi H, Riazirad F, Ajdary S, Shabani A, et al. Assessment of interferon-gamma levels and leishmanin skin test results in persons recovered for leishmaniasis. Am J Trop Med Hyg. 2012;87(1):70-5. doi:10.4269/ ajtmh.2012.11-0479.

23. Reithinger R, Dujardin JC. Molecular diagnosis of leishmaniasis: current status and future applications. J Clin Microbiol. 2007;45(1):21-5. doi:10.1128/JCM.02029-06.

24. Cruz I, Millet A, Carrillo E, Chenik M, Salotra P, Verma S, et al. An approach for interlaboratory comparison of conventional and real-time PCR assays for diagnosis of human leishmaniasis. Exp Parasitol. 2013;134(3):281-9. doi:10.1016/j.exppara.2013.03.026.

25. Odiwuor SO, Saad AA, De Doncker S, Maes I, Laurent T, El Safi $\mathrm{S}$, et al. Universal PCR assays for the differential detection of all Old World Leishmania species. Eur J Clin Microbio Infect Dis. 2011;30(2):209-18. doi:10.1007/s10096-010-1071-3.

26. Toz SO, Culha G, Zeyrek FY, Ertabaklar H, Alkan MZ, Vardarli AT, et al. A real-time ITS1-PCR based method in the diagnosis and species identification of Leishmania parasite from human and dog clinical samples in Turkey. PLoS Negl Trop Dis. 2013;7(5): e2205. doi:10.1371/journal.pntd.0002205.

27. Monroy-Ostria A, Nasereddin A, Monteon VM, Guzman-Bracho C, Jaffe CL. ITS1 PCR-RFLP diagnosis and characterization of Leishmania in clinical samples and strains from cases of human cutaneous leishmaniasis in states of the Mexican Southeast. Interdiscip Perspect Infect Dis. 2014;2014:607287. doi:10.1155/ 2014/607287.

28. Satow MM, Yamashiro-Kanashiro EH, Rocha MC, Oyafuso LK, Soler RC, Cotrim PC, et al. Applicability of kDNA-PCR for routine diagnosis of American tegumentary leishmaniasis in a tertiary reference hospital. Rev Inst Med Trop Sao Paulo. 2013;55(6):393-9. doi:10.1590/S0036-46652013000600004.

29. Jara M, Adaui V, Valencia BM, Martinez D, Alba M, Castrillon $\mathrm{C}$, et al. Real-time PCR assay for detection and quantification of Leishmania (Viannia) organisms in skin and mucosal lesions: exploratory study of parasite load and clinical parameters. J Clin Microbiol. 2013;51(6):1826-33. doi:10.1128/JCM.00208-13.

30. Tsukayama P, Nunez JH, De Los Santos M, Soberon V, Lucas CM, Matlashewski G, et al. A FRET-based real-time PCR assay to identify the main causal agents of New World tegumentary leishmaniasis. PLoS Negl Trop Dis. 2013;7(1):e1956. doi:10. 1371/journal.pntd.0001956.

31. Van der Auwera G, Ravel C, Verweij JJ, Bart A, Schonian G, Felger I. Evaluation of four single-locus markers for Leishmania species discrimination by sequencing. J Clin Microbiol. 2014;52(4):1098-104. doi:10.1128/JCM.02936-13.

32. Khosravi S, Hejazi SH, Hashemzadeh M, Eslami G, Darani HY. Molecular diagnosis of Old World leishmaniasis: real-time PCR based on tryparedoxin peroxidase gene for the detection and identification of Leishmania spp. J Vector Borne Dis. 2012;49(1): $15-8$.

33. Mugasa CM, Laurent T, Schoone GJ, Basiye FL, Saad AA, El Safi $S$, et al. Simplified molecular detection of Leishmania parasites in various clinical samples from patients with leishmaniasis. Parasit Vectors. 2010;3(1):13. doi:10.1186/1756-33053-13.

34. Mugasa CM, Deborggraeve S, Schoone GJ, Laurent T, Leeflang MM, Ekangu RA, et al. Accordance and concordance of PCR and NASBA followed by oligochromatography for the molecular diagnosis of Trypanosoma brucei and Leishmania. Trop Med Intern Health TM IH. 2010;15(7):800-5. doi:10.1111/j.13653156.2010.02547.x.

35. Saad AA, Ahmed NG, Osman OS, Al-Basheer AA, Hamad A, Deborggraeve $S$, et al. Diagnostic accuracy of the Leishmania OligoC-TesT and NASBA-oligochromatography for diagnosis of leishmaniasis in Sudan. PLoS Negl Trop Dis. 2010;4(8):e776. doi:10.1371/journal.pntd.0000776.

36. Adams ER, Schoone GJ, Ageed AF, Safi SE, Schallig HD. Development of a reverse transcriptase loop-mediated isothermal amplification (LAMP) assay for the sensitive detection of Leishmania parasites in clinical samples. Am J Trop Med Hyg. 2010;82(4):591-6. doi:10.4269/ajtmh.2010.09-0369.

37. Nzelu CO, Gomez EA, Caceres AG, Sakurai T, Martini-Robles L, Uezato $\mathrm{H}$, et al. Development of a loop-mediated isothermal amplification method for rapid mass-screening of sand flies for Leishmania infection. Acta Trop. 2014;132:1-6. doi:10.1016/j. actatropica.2013.12.016.

38. Karani M, Sotiriadou I, Plutzer J, Karanis P. Bench-scale experiments for the development of a unified loop-mediated isothermal amplification (LAMP) assay for the in vitro diagnosis of Leishmania species' promastigotes. Epidemiol Infect. 2014;142(8):1671-7. doi:10.1017/S0950268813002677.

39. Verma S, Avishek K, Sharma V, Negi NS, Ramesh V, Salotra P. Application of loop-mediated isothermal amplification assay for the sensitive and rapid diagnosis of visceral leishmaniasis and 
post-kala-azar dermal leishmaniasis. Diagn Microbiol Infect Dis. 2013;75(4):390-5. doi:10.1016/j.diagmicrobio.2013.01.011.

40. Mikita K, Maeda T, Yoshikawa S, Ono T, Miyahira Y, Kawana A. The direct boil-LAMP method: a simple and rapid diagnostic method for cutaneous leishmaniasis. Parasitol Int. 2014;63(6): 785-9. doi:10.1016/j.parint.2014.07.007.

41. Caliendo AM, Gilbert DN, Ginocchio CC, Hanson KE, May L, Quinn TC, et al. Better tests, better care: improved diagnostics for infectious diseases. Clin Infect Dis. 2013;57(Suppl 3):S139-70. doi:10.1093/cid/cit578.

42. Adams ER, Gomez MA, Scheske L, Rios R, Marquez R, Cossio A, et al. Sensitive diagnosis of cutaneous leishmaniasis by lesion swab sampling coupled to qPCR. Parasitology. 2014;141(14): 1891-7. doi:10.1017/S0031182014001280.

43. Kato H, Caceres AG, Mimori T, Ishimaru Y, Sayed AS, Fujita M, et al. Use of FTA cards for direct sampling of patients' lesions in the ecological study of cutaneous leishmaniasis. J Clin Microbiol. 2010;48(10):3661-5. doi:10.1128/JCM.00498-10.

44. Miranda A, Saldana A, Gonzalez K, Paz H, Santamaria G, Samudio F, et al. Evaluation of PCR for cutaneous leishmaniasis diagnosis and species identification using filter paper samples in Panama, Central America. Trans R Soc Trop Med Hyg. 2012;106(9):544-8. doi:10.1016/j.trstmh.2012.05.005.

45. Di Muccio T, Veronesi F, Antognoni MT, Onofri A, Piergili Fioretti D, Gramiccia M. Diagnostic value of conjunctival swab sampling associated with nested PCR for different categories of dogs naturally exposed to Leishmania infantum infection. J Clin Microbiol. 2012;50(8):2651-9. doi:10.1128/JCM.00558-12.

46. Ceccarelli M, Galluzzi L, Sisti D, Bianchi B, Magnani M. Application of qPCR in conjunctival swab samples for the evaluation of canine leishmaniasis in borderline cases or disease relapse and correlation with clinical parameters. Parasit Vectors. 2014;7(1):460. doi:10.1186/PREACCEPT-1290570722137060.

47. Wall EC, Watson J, Armstrong M, Chiodini PL, Lockwood DN. Epidemiology of imported cutaneous leishmaniasis at the Hospital for Tropical Diseases, London, United Kingdom: use of polymerase chain reaction to identify the species. Am J Trop Med Hyg. 2012;86(1):115-8. doi:10.4269/ajtmh.2012.10-0558.

48. Pratlong F, Dereure J, Ravel C, Lami P, Balard Y, Serres G, et al. Geographical distribution and epidemiological features of Old World cutaneous leishmaniasis foci, based on the isoenzyme analysis of 1048 strains. Trop Med Intern Health. 2009;14(9): 1071-85. doi:10.1111/j.1365-3156.2009.02336.x.

49. Chaara D, Haouas N, Dedet JP, Babba H, Pratlong F. Leishmaniases in Maghreb: an endemic neglected disease. Acta Trop. 2014;132:80-93. doi:10.1016/j.actatropica.2013.12.018.

50. Azmi K, Schonian G, Schnur LF, Nasereddin A, Ereqat S, Abdeen Z. Development of assays using hexokinase and phosphoglucomutase gene sequences that distinguish strains of Leishmania tropica from different zymodemes and microsatellite clusters and their application to Palestinian foci of cutaneous leishmaniasis. PLoS Negl Trop Dis. 2013;7(9):e2464. doi:10. 1371/journal.pntd.0002464.

51. Marfurt J, Nasereddin A, Niederwieser I, Jaffe CL, Beck HP, Felger I. Identification and differentiation of Leishmania species in clinical samples by PCR amplification of the miniexon sequence and subsequent restriction fragment length polymorphism analysis. J Clin Microbiol. 2003;41(7):3147-53.

52. Marfurt J, Niederwieser I, Makia ND, Beck HP, Felger I. Diagnostic genotyping of Old and New World Leishmania species by PCR-RFLP. Diagn Microbiol Infect Dis. 2003;46(2):115-24.

53. Kent AD, Dos Santos TV, Gangadin A, Samjhawan A, Mans DR, Schallig HD. Studies on the sand fly fauna (Diptera: Psychodidae) in high-transmission areas of cutaneous leishmaniasis in the Republic of Suriname. Parasit Vectors. 2013;6(1):318. doi:10. 1186/1756-3305-6-318.
54. Dorlo TP, van Thiel PP, Schoone GJ, Stienstra Y, van Vugt M, Beijnen JH, et al. Dynamics of parasite clearance in cutaneous leishmaniasis patients treated with miltefosine. PLoS Negl Trop Dis. 2011;5(12):e1436. doi:10.1371/journal.pntd.0001436.

55. Imani M, Dehkharghani AD, Ghelman M, Mohammadloo M. Molecular technique for detection of Leishmania infantum isolates in Iran. Trop Parasitol. 2014;4(1):35-7. doi:10.4103/22295070.129160

56. Graca GC, Volpini AC, Romero GA, Oliveira Neto MP, Hueb M, Porrozzi R, et al. Development and validation of PCR-based assays for diagnosis of American cutaneous leishmaniasis and identification of the parasite species. Mem Inst Oswaldo Cruz. 2012;107(5):664-74.

57. Fraga J, Veland N, Montalvo AM, Praet N, Boggild AK, Valencia $\mathrm{BM}$, et al. Accurate and rapid species typing from cutaneous and mucocutaneous leishmaniasis lesions of the New World. Diagn Microbiol Infect Dis. 2012;74(2):142-50. doi:10.1016/j. diagmicrobio.2012.06.010.

58. Montalvo AM, Fraga J, El Safi S, Gramiccia M, Jaffe CL, Dujardin JC, et al. Direct Leishmania species typing in Old World clinical samples: evaluation of 3 sensitive methods based on the heat-shock protein 70 gene. Diagn Microbiol Infect Dis. 2014;80(1):35-9. doi:10.1016/j.diagmicrobio.2014.05.012.

59. Votypka J, Kasap OE, Volf P, Kodym P, Alten B. Risk factors for cutaneous leishmaniasis in Cukurova region, Turkey. Trans $\mathrm{R}$ Soc Trop Med Hyg. 2012;106(3):186-90. doi:10.1016/j.trstmh. 2011.12.004.

60. van Thiel PP, Leenstra T, de Vries HJ, van der Sluis A, van Gool T, Krull AC, et al. Cutaneous leishmaniasis (Leishmania major infection) in Dutch troops deployed in northern Afghanistan: epidemiology, clinical aspects, and treatment. Am J Trop Med Hyg. 2010;83(6):1295-300. doi:10.4269/ajtmh.2010.100143.

61. Bart A, van Thiel PP, De Vries HJ, Hodiamont CJ, Van Gool T. Imported leishmaniasis in The Netherlands from 2005 to 2012: epidemiology, diagnostic techniques and sequence-based species typing from 195 patients. Euro Surveill. 2013;18(30):20544.

62. Saberi S, Zamani A, Motamedi N, Nilforoushzadeh MA, Jaffary $\mathrm{F}$, Rahimi E, et al. The knowledge, attitude, and prevention practices of students regarding cutaneous leishmaniasis in the hyperendemic region of the Shahid Babaie Airbase. Vector Borne Zoonotic Dis. 2012;12(4):306-9. doi:10.1089/vbz.2010.0259.

63. Chaves LF, Calzada JE, Valderrama A, Saldana A. Cutaneous leishmaniasis and sand fly fluctuations are associated with el nino in panama. PLoS Negl Trop Dis. 2014;8(10):e3210. doi:10.1371/ journal.pntd.0003210.

64. Croft SL, Sundar S, Fairlamb AH. Drug resistance in leishmaniasis. Clin Microbiol Rev. 2006;19(1):111-26. doi:10.1128/ CMR.19.1.111-126.2006.

65. Schriefer A, Schriefer AL, Goes-Neto A, Guimaraes LH, Carvalho LP, Almeida RP, et al. Multiclonal Leishmania braziliensis population structure and its clinical implication in a region of endemicity for American tegumentary leishmaniasis. Infect Immun. 2004;72(1):508-14.

66. Lucas CM, Franke ED, Cachay MI, Tejada A, Cruz ME, Kreutzer $\mathrm{RD}$, et al. Geographic distribution and clinical description of leishmaniasis cases in Peru. Am J Trop Med Hyg. 1998;59(2): 312-7.

67. Schriefer A, Guimaraes LH, Machado PR, Lessa M, Lessa HA, Lago E, et al. Geographic clustering of leishmaniasis in northeastern Brazil. Emerg Infect Dis. 2009;15(6):871-6. doi:10.3201/ eid1506.080406.

68. Hu RV, Kent AD, Adams ER, van der Veer C, Sabajo LO, Mans DR, et al. First case of cutaneous leishmaniasis caused by Leishmania (Viannia) braziliensis in Suriname. Am J Trop Med Hyg. 2012;86(5):825-7. doi:10.4269/ajtmh.2012.11-0728. 
69. van der Meide W, de Vries H, Pratlong F, van der Wal A, Sabajo L. Leishmaniasis, Suriname. Emerg Infect Dis. 2008;14(5): 857-9. doi:10.3201/eid1405.070433.

70. Gonzalez U, Pinart M, Rengifo-Pardo M, Macaya A, Alvar J, Tweed JA. Interventions for American cutaneous and mucocutaneous leishmaniasis. Cochrane Database Syst Rev. 2009;2:CD004834. doi:10.1002/14651858.CD004834.pub2.

71. Asilian A, Sadeghinia A, Faghihi G, Momeni A. Comparative study of the efficacy of combined cryotherapy and intralesional meglumine antimoniate (Glucantime) vs. cryotherapy and intralesional meglumine antimoniate (Glucantime) alone for the treatment of cutaneous leishmaniasis. Int $\mathrm{J}$ Dermatol. 2004;43(4):281-3. doi:10.1111/j.1365-4632.2004.02002.x.

72. Salmanpour R, Razmavar MR, Abtahi N. Comparison of intralesional meglumine antimoniate, cryotherapy and their combination in the treatment of cutaneous leishmaniasis. Int $\mathrm{J}$ Dermatol. 2006;45(9):1115-6. doi:10.1111/j.1365-4632.2006.02822.x.

73. el Darouti MA, al Rubaie SM. Cutaneous leishmaniasis. Treatment with combined cryotherapy and intralesional stibogluconate injection. Int J Dermatol. 1990;29(1):56-9.

74. Aronson NE, Wortmann GW, Byrne WR, Howard RS, Bernstein WB, Marovich MA, et al. A randomized controlled trial of local heat therapy versus intravenous sodium stibogluconate for the treatment of cutaneous Leishmania major infection. PLoS Negl Trop Dis. 2010;4(3):e628. doi:10.1371/journal.pntd.0000628.

75. Reithinger R, Mohsen M, Wahid M, Bismullah M, Quinnell RJ, Davies CR, et al. Efficacy of thermotherapy to treat cutaneous leishmaniasis caused by Leishmania tropica in Kabul, Afghanistan: a randomized, controlled trial. Clin Infect Dis. 2005;40(8):1148-55. doi:10.1086/428736.

76. Mohebali M, Fotouhi A, Hooshmand B, Zarei Z, Akhoundi B, Rahnema A, et al. Comparison of miltefosine and meglumine antimoniate for the treatment of zoonotic cutaneous leishmaniasis (ZCL) by a randomized clinical trial in Iran. Acta Trop. 2007;103(1):33-40. doi:10.1016/j.actatropica.2007.05.005.

77. van Thiel PP, Leenstra T, Kager PA, de Vries HJ, van Vugt M, van der Meide WF, et al. Miltefosine treatment of Leishmania major infection: an observational study involving Dutch military personnel returning from northern Afghanistan. Clin Infect Dis. 2010;50(1):80-3. doi:10.1086/648726.

78. Velasco-Castrejon O, Walton BC, Rivas-Sanchez B, Garcia MF, Lazaro GJ, Hobart O, et al. Treatment of cutaneous leishmaniasis with localized current field (radio frequency) in Tabasco, Mexico. Am J Trop Med Hyg. 1997;57(3):309-12.

79. Pratlong F, Deniau M, Darie H, Eichenlaub S, Proll S, Garrabe E, et al. Human cutaneous leishmaniasis caused by Leishmania naiffi is wide-spread in South America. Ann Trop Med Parasitol. 2002;96(8):781-5. doi:10.1179/000349802125002293.

80. Escobar P, Matu S, Marques C, Croft SL. Sensitivities of Leishmania species to hexadecylphosphocholine (miltefosine), ET-18-OCH(3) (edelfosine) and amphotericin B. Acta Trop. 2002;81(2):151-7.

81. Soto J, Arana BA, Toledo J, Rizzo N, Vega JC, Diaz A, et al. Miltefosine for new world cutaneous leishmaniasis. Clin Infect Dis. 2004;38(9):1266-72. doi:10.1086/383321.

82. World Health O. Control of the leishmaniases. World Health Organization technical report series. 2010(949):12-13, 1-186 (back cover).

83. Guerra JA, Prestes SR, Silveira H, Coelho LI, Gama P, Moura A, et al. Mucosal leishmaniasis caused by Leishmania (Viannia) braziliensis and Leishmania (Viannia) guyanensis in the Brazilian Amazon. PLoS Negl Trop Dis. 2011;5(3):e980. doi:10.1371/ journal.pntd.0000980.
84. Neves LO, Talhari AC, Gadelha EP, Silva Junior RM, Guerra JA, Ferreira LC, et al. A randomized clinical trial comparing meglumine antimoniate, pentamidine and amphotericin $\mathrm{B}$ for the treatment of cutaneous leishmaniasis by Leishmania guyanensis. An Bras Dermatol. 2011;86(6):1092-101.

85. Gangneux JP, Sauzet S, Donnard S, Meyer N, Cornillet A, Pratlong F, et al. Recurrent American cutaneous leishmaniasis. Emerg Infect Dis. 2007;13(9):1436-8. doi:10.3201/eid1309. 061446.

86. Dedet JP, Pradinaud R, Gay F. Epidemiological aspects of human cutaneous leishmaniasis in French Guiana. Trans R Soc Trop Med Hyg. 1989;83(5):616-20.

87. Soto J, Rea J, Balderrama M, Toledo J, Soto P, Valda L, et al. Efficacy of miltefosine for Bolivian cutaneous leishmaniasis. Am J Trop Med Hyg. 2008;78(2):210-1.

88. Chrusciak-Talhari A, Dietze R, Chrusciak Talhari C, da Silva RM, Gadelha Yamashita EP, de Oliveira Penna G, et al. Randomized controlled clinical trial to access efficacy and safety of miltefosine in the treatment of cutaneous leishmaniasis Caused by Leishmania (Viannia) guyanensis in Manaus, Brazil. Am J Trop Med Hyg. 2011;84(2):255-60. doi:10.4269/ajtmh.2011.100155 .

89. Machado PR, Ampuero J, Guimaraes LH, Villasboas L, Rocha AT, Schriefer A, et al. Miltefosine in the treatment of cutaneous leishmaniasis caused by Leishmania braziliensis in Brazil: a randomized and controlled trial. PLoS Negl Trop Dis. 2010;4(12):e912. doi:10.1371/journal.pntd.0000912.

90. Amato VS, Tuon FF, Imamura R, Abegao de Camargo R, Duarte MI, Neto VA. Mucosal leishmaniasis: description of case management approaches and analysis of risk factors for treatment failure in a cohort of 140 patients in Brazil. JEADV. 2009;23(9):1026-34. doi:10.1111/j.1468-3083.2009.03238.x.

91. Nonata R, Sampaio R, Marsden PD. Mucosal leishmaniasis unresponsive to glucantime therapy successfully treated with Am Bisome. Trans R Soc Trop Med Hyg. 1997;91(1):77.

92. Soto J, Toledo J, Valda L, Balderrama M, Rea I, Parra R, et al. Treatment of Bolivian mucosal leishmaniasis with miltefosine. Clin Infect Dis. 2007;44(3):350-6. doi:10.1086/510588.

93. Lessa HA, Machado P, Lima F, Cruz AA, Bacellar O, Guerreiro $\mathrm{J}$, et al. Successful treatment of refractory mucosal leishmaniasis with pentoxifylline plus antimony. Am J Trop Med Hyg. 2001; 65(2):87-9.

94. Machado PR, Lessa H, Lessa M, Guimaraes LH, Bang H, Ho JL, et al. Oral pentoxifylline combined with pentavalent antimony: a randomized trial for mucosal leishmaniasis. Clin Infect Dis. 2007;44(6):788-93. doi:10.1086/511643.

95. Stockdale L, Newton R. A review of preventative methods against human leishmaniasis infection. PLoS Negl Trop Dis. 2013;7(6):e2278. doi:10.1371/journal.pntd.0002278.

96. Werneck GL, Costa CH, de Carvalho FA, Pires ECMS, Maguire $\mathrm{JH}$, Castro MC. Effectiveness of insecticide spraying and culling of dogs on the incidence of Leishmania infantum infection in humans: a cluster randomized trial in Teresina, Brazil. PLoS Negl Trop Dis. 2014;8(10):e3172. doi:10.1371/journal.pntd.0003172.

97. Orellano PW, Vazquez N, Salomon OD. Cost-effectiveness of prevention strategies for American tegumentary leishmaniasis in Argentina. Cad Saude Publica. 2013;29(12):2459-72.

98. Sundar S, Singh B. Identifying vaccine targets for anti-leishmanial vaccine development. Expert Rev Vaccines. 2014;13(4): 489-505. doi:10.1586/14760584.2014.894467.

99. Sacks DL. Vaccines against tropical parasitic diseases: a persisting answer to a persisting problem. Nat Immunol. 2014;15(5):403-5. doi:10.1038/ni.2853. 